\title{
Safety and tolerability of nevirapine-based antiretroviral therapy in HIV-infected patients receiving fluconazole for cryptococcal prophylaxis: a retrospective cohort study

\author{
Weerawat Manosuthi*1, Nopphanath Chumpathat ${ }^{1}$, Achara Chaovavanich ${ }^{1}$ \\ and Somnuek Sungkanuparph ${ }^{2}$
}

Address: ${ }^{1}$ Bamrasnaradura Institute, Ministry of Public Health, Nonthaburi, 11000, Thailand and ${ }^{2}$ Faculty of Medicine Ramathibodi Hospital, Mahidol University, Bangkok, 10400, Thailand

Email: Weerawat Manosuthi* - drweerawat@hotmail.com; Nopphanath Chumpathat - tanaat@hotmail.com;

Achara Chaovavanich - achara@health.moph.go.th; Somnuek Sungkanuparph - tesuk@mahidol.ac.th

* Corresponding author

Published: 24 August 2005

BMC Infectious Diseases 2005, 5:67 doi:10.1 186/147|-2334-5-67
Received: 29 May 2005

Accepted: 24 August 2005

This article is available from: http://www.biomedcentral.com/I47I-2334/5/67

(C) 2005 Manosuthi et al; licensee BioMed Central Ltd.

This is an Open Access article distributed under the terms of the Creative Commons Attribution License (http://creativecommons.org/licenses/by/2.0), which permits unrestricted use, distribution, and reproduction in any medium, provided the original work is properly cited.

\begin{abstract}
Background: To compare the adverse events after initiation of nevirapine-based ART among HIVinfected patients who did not receive fluconazole (group A), received fluconazole $400 \mathrm{mg} /$ week (group B), and received fluconazole $200 \mathrm{mg} /$ day (group C).
\end{abstract}

Methods: A retrospective cohort study was conducted among HIV-infected patients who began NVP-based ART between December 2003 and September 2004. Patients were followed up for 6 months. Clinical hepatitis, elevated aspartate aminotransferase (AST) and alanine aminotransferase (ALT) (> 3 times from baseline), and skin rashes were studied.

Results: There were 686 patients; 225, 392, and 69 patients in group A, B, and C, respectively. Baseline characteristics including age, previous opportunistic infections, use of antituberculous drugs, and baseline aminotransferase levels among the three groups were similar. Group $C$ had a higher proportion of men $(p=0.016)$. Baseline median (IQR) CD4 cell counts were $85(2 I-159)$, $18(7-48)$, and $16(5-35)$ cell $/ \mathrm{mm}^{3}$ in group $A, B$, and $C$, respectively $(p<0.00 \mathrm{I})$. Of $2 / 225(0.9 \%)$, $4 / 392(1.0 \%)$, and $0 / 69(0 \%)$ patients in group $A, B$, and $C$ developed clinical hepatitis $(p=0.705)$. There were no significant difference of elevated AST or ALT among the three groups $(p>0.05)$. By logistic regression, receiving fluconazole was not predictive of clinical hepatitis, elevated aminotransferase, or skin rashes. At 6 months after initiating NVP, 174 (77.3\%) patients in group A, 309 (78.8\%) patients in group B, and 58 (84.1\%) patients in group C remained on NVP.

Conclusion: Initiation of NVP-based ART among Thais with advance HIV disease receiving fluconazole is safe and well-tolerated. nevirapine should not be contraindicated for patients receiving fluconazole for treatment or prophylaxis of cryptococcosis. 


\section{Background}

Highly active antiretroviral therapy (HAART) has been widely used for the treatment of human immunodeficiency virus (HIV) infected patients with successful immune restoration and reductions in morbidity and mortality $[1,2]$. However, access to antiretroviral therapy for HIV-infected patients in resource-limited countries is still a major obstacle [3,4]. HIV-infected patients in these areas often presented with advanced HIV disease. Nevirapine (NVP) is a non-nucleoside reverse transcriptase inhibitor (NNRTI) that has shown efficacy even in advanced HIV disease [5-8]. NVP-based HAART has been widely used in the resource-limited countries because of its efficacy, relative low cost, and availability. Additionally, NVP is part of two of the four World Health Organization-recommended generic combinations for the $3 \times 5$ program in resource-limited countries [9]. NVP-related adverse events particularly skin rashes and hepatotoxicity have been well recognized as the limitation of NVP use [10-12]. NVP-associated skin rashes usually appear after one to four weeks of treatment [10]. The risk of hepatotoxicity is greatest in the first six weeks of treatment and continues through 18 weeks of treatment [13].

Fluconazole is a commonly used for the prophylaxis and treatment of cryptococcosis in HIV-infected patients. Fluconazole $400 \mathrm{mg} /$ day has been used as standard therapy for treatment of cryptocoocal meningitis after completion of two weeks of amphotericin B [12]. Fluconazole 200 $\mathrm{mg} /$ day is used for secondary prophylaxis until immune reconstitution occurs with HAART [14]. Fluconazole 400 $\mathrm{mg} /$ week is recommended for primary prophylaxis among HIV-infected patients with CD4 cell count $<100$ cells $/ \mathrm{mm}^{3}$ in Thailand and some developing countries because of a high prevalence of cryptococcosis and the evidence of a survival benefit [15]. Nonetheless, the potential drug-drug interaction between NVP and fluconazole is a major concern. Both drugs can induce cytochrome P450 isoenzymes in the liver [16-18]. Geel et al recently reported that fluconazole significantly raised plasma NVP levels and may cause serious hepatotoxicity [19]. So far, there have not been enough data or any recommendations to adjust NVP dosage for the concomitant use of both drugs in order to avoiding adverse events. A previous study demonstrated that genetic disposition may play a role in NVP hypersensitivity reactions [20]. There is little data of safety and tolerability for concurrent use of NVP and fluconazole in Asian populations. We therefore conducted this retrospective cohort study to compare the frequencies of hepatotoxicity and skin rashes among HIVinfected patients who received fluconazole and subsequently received NVP-based HAART regimens.

\section{Methods}

A retrospective cohort study was conducted among antiretroviral-naïve HIV-infected patients who began a NVP-based HAART regimens between December 2003 and September 2004 at Bamrasnaradura Institute, Ministry of Public Health, Nonthaburi, Thailand. Inclusion criteria were as follows: (1) HIV-infected patients > 15 years of age, (2) naïve to antiretroviral therapy, (3) began antiretroviral therapy with a NVP-based HAART regimen, (4) used NVP 200-mg once-daily lead-in dose, prior to escalation to $200 \mathrm{mg}$ twice daily. Each eligible patient was classified into one of three groups according to whether he or she received fluconazole or not and the different dosages of fluconazole as follows: not received fluconazole (group A), received fluconazole $400 \mathrm{mg} /$ week (group B), and received fluconazole $200 \mathrm{mg} /$ day (group C). All patients were followed for 6 months after initiating NVPbased HAART. The primary objective was to compare the frequency of clinical hepatitis among the three groups. The secondary objectives of interest were to compare the frequencies of elevated aspartate aminotransferase (AST) and alanine aminotransferase (ALT) $>$ three times from baseline at six months after initiation of NVP and to compare the frequencies skin rashes among the three groups.

The patients' clinical statuses including clinical hepatitis and skin rashes were assessed monthly by the attending physician. Liver functions test was performed at 6 months after initiating NVP in case of no evidence of hepatitis. Clinical hepatitis was defined as symptomatic hepatitis and either AST or ALT elevated > five times the upper limit of normal. Signs and symptoms of hepatitis may include anorexia, malaise, jaundice, nausea/vomiting, hepatomegaly, and hepatic tenderness. Skin rash was determined by medical record of skin reactions including diffuse erythematous or maculopapular rash, urticarial rash, serum sickness-like reaction, Stevens-Johnson syndrome, and toxic epidermal necrolysis.

Mean ( \pm standard deviation, SD), median (interquartile range, IQR) and frequencies (\%) were used to describe patients' characteristics in each treatment groups. Chisquare test and Kruskal-Walis test were used to compare categorical and continuous variables among the treatment groups, respectively. Logistic regression was used to determine predicting factors for each adverse event of interest. The possible risk factors were entered into the model of binary logistic regression. Spearman correlation was use to study the relationship between skin rashes and clinical hepatitis, skin rashes and aminotransferase levels. All analyses were performed using SPSS program version 11.5. A $P$ value less than 0.05 was considered statistically significant. The study was approved from the institute review board. 
Table I: Baseline characteristic of 686 patients receiving NVP-based HAART.

\begin{tabular}{|c|c|c|c|c|}
\hline \multirow[t]{2}{*}{ Baseline characteristics } & \multirow{2}{*}{$\begin{array}{l}\text { Not receiving } \\
\text { fluconazole } \\
(n=225)\end{array}$} & \multicolumn{2}{|c|}{ Receiving fluconazole } & \multirow[t]{2}{*}{$P$ value } \\
\hline & & $400 \mathrm{mg} /$ week $(n=392)$ & $200 \mathrm{mg} / \mathrm{day}(n=69)$ & \\
\hline Gender: Male & $116(51.6 \%)$ & $213(54.3 \%)$ & 49 (7I.0\%) & 0.016 \\
\hline Female & $109(48.4 \%)$ & $179(45.7 \%)$ & $20(29.0 \%)$ & \\
\hline Age, years, mean $\pm S D$ & $36.0 \pm 7.5$ & $35.0 \pm 7.4$ & $34.7 \pm 8.03$ & 0.200 \\
\hline Weight, kg., mean \pm SD & $54.9 \pm 10.6$ & $52.3 \pm 10.0$ & $51.4 \pm 8.7$ & 0.008 \\
\hline \multicolumn{5}{|l|}{ Previous opportunistic infections, patients (\%) } \\
\hline Any major opportunistic infections & $53(23.6 \%)$ & $120(30.6 \%)$ & $24(34.8 \%)$ & 0.368 \\
\hline Tuberculosis & $32(14.2 \%)$ & $64(16.3 \%)$ & $17(24.6 \%)$ & 0.124 \\
\hline PCP & 31 (13.8\%) & $47(12.0 \%)$ & $8(11.6 \%)$ & 0.787 \\
\hline Histoplasmosis & $3(1.3 \%)$ & $\mathrm{I}(0.3 \%)$ & - & 0.190 \\
\hline Penicilliosis & $3(1.3 \%)$ & $0(0.0 \%)$ & - & 0.046 \\
\hline Toxoplasmosis & - & $5(1.3 \%)$ & - & 0.151 \\
\hline MAC & $2(0.9 \%)$ & $2(0.5 \%)$ & - & 0.669 \\
\hline \multicolumn{5}{|l|}{ Concurrent medication } \\
\hline Cotrimoxazole & $176(78.2 \%)$ & $363(93.3 \%)$ & 57 (82.6\%) & $<0.001$ \\
\hline Antituberculous drugs & $47(20.9 \%)$ & $82(20.9 \%)$ & $22(31.9 \%)$ & 0.095 \\
\hline Baseline $\mathrm{CD}_{4}$ cell count, cell $/ \mathrm{mm}^{3}$, median (IQR) & $85(21-159)$ & $18(7-48)$ & $16(5-35)$ & $<0.001$ \\
\hline Baseline \% CD4, median (IQR) & $7(2-11)$ & $2(I-5)$ & $2(I-5)$ & $<0.001$ \\
\hline Baseline plasma HIV RNA, & 207,500 & 270,000 & 169,000 & 0.095 \\
\hline copies/ml, median (IQR) & $(68,375-549,500)$ & $(I 18,000-545,000)$ & $(76,750-415,000)$ & \\
\hline Baseline AST, U/L, median (IQR) & $31(23-46.5)$ & $32(25-53.2)$ & $34(24-53)$ & 0.358 \\
\hline Baseline ALT, U/L, median (IQR) & $23(17-39)$ & $28(17-45)$ & $32(17-49.5)$ & 0.177 \\
\hline Baseline TB, mg/dl, median (IQR) & $0.5(0.4-0.65)$ & $0.5(0.4-0.7)$ & $0.5(0.4-0.8)$ & 0.843 \\
\hline
\end{tabular}

\section{Results}

A total of 686 patients were eligible and included in the study. Of 686 patients; 225, 392, and 69 patients were classified into group A, B, and C, respectively. The baseline characteristics of patients prior to initiation of HAART are described and compared among the three groups as shown in Table 1. Baseline characteristics including age, previous major opportunistic infections (OIs), use for antituberculous drugs therapy, baseline AST and ALT, and baseline HIV RNA prior to HAART were not different among the three groups. Group $\mathrm{C}$ patients had a greater proportion of men than the other groups $(p=0.016)$. Group B and group C patients had more advanced HIV disease [i.e., lower body weight $(p=0.008)$, lower baseline CD4 cell counts prior to initiation of HAART $(p<$ $0.001)$, and higher proportion receiving co-trimoxazole $(p$ $<0.001)$ ] than patients in group A.

One hundred and four of 255 (40.8\%) in group A, 188 of $392(48.0 \%)$ in group B, and 36 of $69(52.2 \%)$ in group C had AST testing at 6 months after initiating NVP. Seventy one of $255(29.4 \%), 95$ of $392(24.2 \%)$, and 22 of 69 $(31.9 \%)$ in corresponding groups had ALT testing at 6 months after initiating NVP. The prevalence of patients who developed adverse events including clinical hepatitis, AST and ALT increase $>3$ times from baseline, and skin rashes are shown in Table 2. The prevalence of clinical hepatitis, elevated AST, and elevated ALT were not different among the three groups $(p>0.05)$. There was a significant difference among the groups in the prevalence of skin rashes $(p=0.016)$.

Results of logistic regression analysis indicated that receiving anti-tuberculous drugs was a significant predictor of clinical hepatitis $(p=0.025)$ (Table 3$)$. Gender, body weight, baseline CD4 cell counts, or receiving fluconazole were not predictive of clinical hepatitis. Logistic regression analyses of models including gender, body weight, baseline CD4 cell count, receiving anti-tuberculous drugs, and receiving fluconazole, were not significant predictors of elevated AST $>3$ times from baseline $\left(\chi^{2}(5, N=328)=\right.$ $3.72, p=0.592)$ and elevated ALT $>3$ times from baseline $\left(\chi^{2}(5, \mathrm{~N}=188)=7.26, p=0.298\right)$. Logistic regression analysis of skin rashes indicated that receiving anti-tuberculous drugs was a significant predictor of skin rashes 
Table 2: Frequency of adverse events among the three groups.

\begin{tabular}{|c|c|c|c|c|}
\hline \multirow[t]{2}{*}{ Adverse events } & \multirow{2}{*}{$\begin{array}{l}\text { Not receiving fluconazole } \\
\qquad(n=225)\end{array}$} & \multicolumn{2}{|c|}{ Receiving fluconazole } & \multirow[t]{2}{*}{$P$ value } \\
\hline & & $400 \mathrm{mg} /$ week $(n=392)$ & $200 \mathrm{mg} /$ day $(n=69)$ & \\
\hline Clinical hepatitis & $2 / 225(0.9 \%)$ & $4 / 392(1.0 \%)$ & $0 / 69(0 \%)$ & 0.705 \\
\hline Elevated AST > 3 times from baseline & $3 / 104(2.9 \%)$ & $5 / 188(2.7 \%)$ & $3 / 36(8.3 \%)$ & 0.192 \\
\hline Elevated ALT > 3 times from baseline & $6 / 7 \mid(8.5 \%)$ & $7 / 95(7.4 \%)$ & $2 / 22(9.1 \%)$ & 0.938 \\
\hline Skin Rash & $23 / 225(10.2 \%)$ & $27 / 392(6.9 \%)$ & $0 / 69(0 \%)$ & 0.016 \\
\hline
\end{tabular}

Table 3: Logistic regression of possible risk factors and clinical hepatitis

\begin{tabular}{lccc}
\hline Risk factors & Odd Ratios & 95\% confidence interval & $P$ value \\
\hline Female gender & 1.25 & $0.21-7.49$ & 0.809 \\
Body weight & 1.08 & $0.98-1.17$ & 0.076 \\
Baseline CD4 cell count & 0.99 & $0.97-1.01$ & 0.352 \\
Receiving anti-tuberculous drugs & 7.42 & $1.27-43.31$ & 0.026 \\
Receiving fluconazole & 1.12 & $0.18-6.90$ & 0.901 \\
Receiving Cotrimoxazole & 0.84 & $0.21-5.44$ & 0.675 \\
\hline
\end{tabular}

Table 4: Logistic regression of possible risk factors and skin rashes.

\begin{tabular}{|c|c|c|c|}
\hline Factors & Odd Ratios & $\mathbf{9 5} \%$ confidence interval & $P$ value \\
\hline Female gender & 1.26 & $0.67-2.39$ & 0.470 \\
\hline Body weight & 1.02 & $0.98-1.05$ & 0.347 \\
\hline Baseline CD4 cell count & 1.00 & $0.99-1.01$ & 0.873 \\
\hline Receiving anti-tuberculous drugs & 2.96 & $1.04-8.47$ & 0.043 \\
\hline Receiving fluconazole & 1.56 & $0.79-3.08$ & 0.201 \\
\hline Receiving Cotrimoxazole & 1.21 & $0.68-2.91$ & 0.594 \\
\hline
\end{tabular}

(Table 4). Gender, body weight, baseline CD4 cell counts, or receiving fluconazole were not predictive of skin rashes.

The results of correlation analyses show that there was no correlation between skin rashes and clinical hepatitis $\left(\mathrm{r}_{\mathrm{s}}=\right.$ $0.026, p=0.491)$, skin rashes and AST $\left(r_{s}=0.003, p=\right.$ $0.948)$, or skin rashes and ALT $\left(r_{s}=0.034, p=0.637\right)$. The tolerability of NVP-based HAART is shown in Table 5. Regarding NVP-associated skin rashes, the majority (> $90 \%$ ) of patients developed diffuse maculopapular rashes. Only 1 of 25 patient in group A and 2 of 26 patients in groups B developed Steven-Johnson syndromes. Nine patients died, 1 in group A and 8 in group B. The majority of patients died from opportunistic infections (i.e., 2 cryptococcosis, 2 bacterial pneumonitis,
1 Mycobacterium avium complex infection, and 3 wasting syndromes). No patient died from hepatitis.

\section{Discussion}

In the present study, we have shown that the prevalence of clinical hepatitis and AST and ALT elevation 6 months after initiating HAART among HIV-infected patients who concurrently received NVP and fluconazole were not different from those who received NVP- based HAART without fluconazole. These findings suggest that administration of NVP-based HAART regimens in HIVinfected patients who receive fluconazole dose not increase the risk of hepatotoxicity. The prevalence of clinical hepatitis and aminotransferase elevations in our study was lower than that reported in studies conducted in African HIV-infected patients $[19,20]$. There may be several 
Table 5: Tolerability of NVP-based HAART among the three groups.

\begin{tabular}{|c|c|c|c|c|}
\hline \multirow[t]{2}{*}{ Tolerability outcomes } & \multirow{2}{*}{$\begin{array}{l}\text { Not receiving fluconazole } \\
\qquad(n=225)\end{array}$} & \multicolumn{2}{|c|}{ Receiving fluconazole } & \multirow[t]{2}{*}{$P$ value } \\
\hline & & 400 mg/week $(n=392)$ & $200 \mathrm{mg} / \mathrm{day}(n=69)$ & \\
\hline On NVP-based HAART at six months & 174 (77.3\%) & $309(78.8 \%)$ & $58(84.1 \%)$ & 0.532 \\
\hline Reasons of discontinuation & & & & 0.448 \\
\hline Adverse events & $26(11.5 \%)$ & 29 (7.4\%) & $3(4.3 \%)$ & \\
\hline Skin rashes & $25 / 26(96.2 \%)$ & $26 / 29(89.7 \%)$ & 3 of $3(100.0 \%)$ & \\
\hline Hepatotoxicity & $\mathrm{I} / 26(2.8 \%)$ & $3 / 29(10.3 \%)$ & - & \\
\hline Death & $\mathrm{I}(0.4 \%)$ & $8(2.0 \%)$ & - & \\
\hline Loss to follow-up & $20(8.9 \%)$ & $39(9.9 \%)$ & $7(10.1 \%)$ & \\
\hline Refer & $4(1.8 \%)$ & $7(1.8 \%)$ & I (I.4\%) & \\
\hline
\end{tabular}

explanations for this discrepancy. First, the patients in this study had very low CD4 cell counts (i.e., 97\% had CD4 cell counts $<200$ cells $/ \mathrm{mm}^{3}$ and $80 \%$ had CD 4 cell counts $<100$ cells $/ \mathrm{mm}^{3}$ ). High CD4 cell count is a predictor of hepatotoxicity $[11,19]$. Second, there was a higher proportion of men in our study than the previous studies $[17,18]$. CD4 cell counts are more predictive of hepatotoxicity among men than women (i.e., men who have a CD4 cell counts $>400$ cells $/ \mathrm{mm}^{3}$ are at a greater risk of hepatitis than women with CD4 cell counts > 250 cells $/ \mathrm{mm}^{3}$ ) $[13,21]$. Third, our study included Asians, which was different from the previous study $[11,17,18]$. Sanne et al reported that African women may have an increased likelihood of hepatotoxicity [20]. The previous studies demonstrate that there are differences in drug and alcohol metabolism that may be related to genetic or environmental factors (e.g., differences in diet and protein intake) [2224]. There is little data on differences in NVP metabolism based on genetic disposition.

While logistic regression analyses in the present study show that receiving fluconazole was not predictive for any adverse events, receiving anti-tuberculous drugs was significantly predictive for both clinical hepatitis and skin rashes. The patients in our large cohort had overall $16 \%$ of concurrent tuberculosis and the results from the regression analyses can demonstrate this important issue. These findings point out that concurrent concomitant use of NVP and anti-tuberculous drugs may a cause of more concern. We suggest to closely monitoring liver function test in patients with concomitant use of NVP and anti-tuberculous drugs. Further well-designed prospective study is needed.

Regarding NVP-associated skin rashes, the overall prevalence in the present study was similar to previous study in Thai patients with advanced HIV disease [25]. The incidence of NVP-associated skin rashes in the patients who received Fluconazole was lower than the other groups. This may be explained by the lower CD4 cells count in this group. As the previous studies have demonstrated that persons with a higher baseline CD4 cell counts are likely to develop rash from NVP [26]. Given there was no correlation between skin rashes and clinical hepatitis or elevated aminotransferase, these two entities of adverse events may need different approaches for monitoring and management.

Overall about $80 \%$ of the patients in our cohort continued on NVP-based HAART at six months. Although all patients were initiated with NVP 200-mg once-daily leadin dose prior to escalation to $200 \mathrm{mg}$ twice daily, skin rash was still the major adverse event led to discontinuation of NVP-based HAART. The previous studies using shortcourse prednisolone were failed to prevent NVP-associated skin rashes $[26,27]$. The further study to minimize this major limitation is needed.

NVP-based HAART is a common regimen which widely used for treatment of HIV-infected patients in resourcelimited countries due to its affordability. Until the other options are more accessible, NVP-based HAART is still a key regimen to scale up treatment of HIV in resource-limited countries. Our study may provide the safety data of concomitant use of NVP and fluconazole and support the use of NVP in patients receiving fluconazole for treatment or prophylaxis of cryptococcal diseases.

The limitation of the present study is the nature of retrospective study that patients' clinical status may be underreported. First, not all patients had been checked for aminotransferase level during the first 6 months. Only 328 and 188 patients had been checked for AST and ALT levels, respectively. However, we had analyzed the demographics and adverse events between patients who had and did not have AST or ALT levels and found that there 
were no statistically significant differences. We did not have data of plasma NVP level in this cohort due to retrospective nature. However, Dailly et al reported that there was no association between plasma NVP level and hepatotoxicity [28]. Ultimately, the present study did not assess patients who initiated NVP while received fluconazole $400 \mathrm{mg} / \mathrm{day}$.

\section{Conclusion}

In summary, receiving of fluconazole for treatment or prophylaxis of cryptococcosis does not increase the risk of hepatotoxicity, elevated aminotransferase, or skin rashes from NVP. Initiation of NVP-based HAART among HIVinfected patients receiving fluconazole is safe and well-tolerated. Use of anti-tuberculous drugs is predictive of clinical hepatitis and skin rashes. Initiation of NVP-based HAART in HIV-infected patients receiving anti-tuberculous needs closely monitoring and prompt management.

\section{List of abbreviations}

HAART: Highly active anti-retroviral therapy, HIV: Human immunodeficiency virus, NVP: Nevirapine, NNRTI: Non-nucleoside reverse transcriptase inhibitor, AST: Aspartate aminotransferase, ALT: Alanine aminotransferase

\section{Competing interests}

The author(s) declare that they have no competing interests.

\section{Authors' contributions}

WM participated in the design of the study. NC performed statistical analysis. AC participated in the design of the study. SS participated in the design of the study and statistical analysis.

\section{Acknowledgements}

We would like to thank all the study patients in this study and all the attending staffs in Department of Medicine, Bamrasnaradura Institute. The authors would like to thank Michael Martin for his comments.

\section{References}

I. Hogg RS, Heath KV, Yip B, Craib KJ, O'Shaughnessy MV, Schechter MT, Montaner JS: Improved survival among HIV-infected individuals following initiation of antiretroviral therapy. Jama 1998, 279:450-454.

2. Palella FJJ, Delaney KM, Moorman AC, Loveless MO, Fuhrer J, Satten GA, Aschman DJ, Holmberg SD: Declining morbidity and mortality among patients with advanced human immunodeficiency virus infection. HIV Outpatient Study Investigators. N Engl J Med 1998, 338:853-860.

3. Dionisio D, Esperti F, Messeri D, Vivarelli A: Priority strategies for sustainable fight against HIVIAIDS in low-income countries. Curr HIV Res 2004, 2:377-393.

4. Vermund SH, Powderly WG: Developing a human immunodeficiency virus/acquired immunodeficiency syndrome therapeutic research agenda for resource-limited countries: a consensus statement. Clin Infect Dis 2003, 37:S4-I 2.

5. Floridia M, Bucciardini R, Ricciardulli D, Fragola V, Pirillo MF, Weimer LE, Tomino C, Giannini G, Galluzzo CM, Andreotti M, Cargnel A, Alberici F, De Rienzo B, Leoncini F, Fiaccadori F, Francisci D, Grillone
W, Ortona L, Piazza M, Scalzini A, Nigra E, Tumietto F, Vella S: A randomized, double-blind trial on the use of a triple combination including nevirapine, a nonnucleoside reverse transcriptase HIV inhibitor, in antiretroviral-naive patients with advanced disease. J Acquir Immune Defic Syndr Hum Retrovirol 1999, 20:11-19.

6. Manosuthi W, Sungkanuparph S, Vibhagool A, Rattanasiri S, Thakkinstian A: Nevirapine- versus efavirenz-based highly active antiretroviral therapy regimens in antiretroviral-naive patients with advanced HIV infection. HIV Med 2004, 5:105-109.

7. Podzamczer D, Ferrer E, Consiglio E, Gatell JM, Perez P, Perez JL, Luna E, Gonzalez A, Pedrol E, Lozano L, Ocana I, Llibre JM, Casiro A, Aranda M, Barrufet P, Martinez-Lacasa J, Miro JM, Badia X, Casado A, Lupo S, Cahn P, Manos M, Estela J: A randomized clinical trial comparing nelfinavir or nevirapine associated to zidovudinel lamivudine in HIV-infected naive patients (the Combine Study). Antivir Ther 2002, 7:81-90.

8. van Leth F, Phanuphak P, Ruxrungtham K, Baraldi E, Miller S, Gazzard B, Cahn P, Lalloo UG, van der Westhuizen IP, Malan DR, Johnson MA, Santos BR, Mulcahy F, Wood R, Levi GC, Reboredo G, Squires K, Cassetti I, Petit D, Raffi F, Katlama C, Murphy RL, Horban A, Dam JP, Hassink E, van Leeuwen R, Robinson P, Wit FW, Lange JM: Comparison of first-line antiretroviral therapy with regimens including nevirapine, efavirenz, or both drugs, plus stavudine and lamivudine: a randomised open-label trial, the 2 NN Study. Lancet 2004, 363: I 253-1263.

9. Scaling up Antiretroviral Therapy in Resource-limited Settings: Treatment Guidelines for a public Health Approach. Geneva, Joint United Nations Programme on HIVIAIDS (UNAIDS) and World Health Organization (WHO); 2003.

10. Milinkovic A, Martinez E: Nevirapine in the treatment of HIV. Expert Rev Anti Infect Ther 2004, 2:367-373.

II. Pollard RB, Robinson P, Dransfield K: Safety profile of nevirapine, a nonnucleoside reverse transcriptase inhibitor for the treatment of human immunodeficiency virus infection. Clin Ther 1998, 20:107|-1092.

12. Knudtson E, Para M, Boswell H, Fan-Havard P: Drug rash with eosinophilia and systemic symptoms syndrome and renal toxicity with a nevirapine-containing regimen in a pregnant patient with human immunodeficiency virus. Obstet Gynecol 2003, 101:1094-1097.

13. Stern JO, Robinson PA, Love J, Lanes S, Imperiale MS, Mayers DL: A comprehensive hepatic safety analysis of nevirapine in different populations of HIV infected patients. J Acquir Immune Defic Syndr 2003, 34 Suppl I:S2I-33.

14. Saag MS, Graybill RJ, Larsen RA, Pappas PG, Perfect JR, Powderly WG, Sobel JD, Dismukes WE: Practice guidelines for the management of cryptococcal disease. Infectious Diseases Society of America. Clin Infect Dis 2000, 30:710-7/8.

15. Chetchotisakd $P$, Sungkanuparph $S$, Thinkhamrop $B$, Mootsikapun $P$, Boonyaprawit P: A multicentre, randomized, double-blind, placebo-controlled trial of primary cryptococcal meningitis prophylaxis in HIV-infected patients with severe immune deficiency. HIV Med 2004, 5: I 40-I 43.

16. Albengres E, Le Louet H, Tillement JP: Systemic antifungal agents. Drug interactions of clinical significance. Drug Saf 1998, 18:83-97.

17. Kuper JI, D'Aprile M: Drug-Drug interactions of clinical significance in the treatment of patients with Mycobacterium avium complex disease. Clin Pharmacokinet 2000, 39:203-2। 4 .

18. Joly $V$, Yeni $P$ : [Non-nucleoside reverse transcriptase inhibitors]. Ann Med Interne (Paris) 2000, I 5 I:260-267.

19. Geel J, Pitt J, Orrell C], Van Dyk M, Wood R: The effect of fluconazole on nevirapine pharmacokinetics: July I I-I6; Bangkok. Volume I. ; 2004:369.

20. Sanne I, Mommeja-Marin H, Hinkle J, Bartlett JA, Lederman MM, Maartens G, Wakeford C, Shaw A, Quinn J, Gish RG, Rousseau F: Severe hepatotoxicity associated with nevirapine use in HIVinfected subjects. J Infect Dis 2005, 1 9 1:825-829.

21. Reisler K: High hepatotoxicity rate seen among HAART patients. AIDS Alert 2001, 16:118-119.

22. Stranges S, Freudenheim JL, Muti P, Farinaro E, Russell M, Nochajski $\mathrm{TH}$, Trevisan M: Greater hepatic vulnerability after alcohol intake in African Americans compared with Caucasians: a population-based study. J Natl Med Assoc 2004, 96: I I85-I I 92. 
23. Ma B, Yeo W, Hui P, Ho WM, Johnson PJ: Acute toxicity of adjuvant doxorubicin and cyclophosphamide for early breast cancer -- a retrospective review of Chinese patients and comparison with an historic Western series. Radiother Oncol 2002, 62:185-189.

24. Critchley JA, Nimmo GR, Gregson CA, Woolhouse NM, Prescott LF: Inter-subject and ethnic differences in paracetamol metabolism. Br J Clin Pharmacol 1986, 22:649-657.

25. Anekthananon T, Ratanasuwan W, Techasathit W, Sonjai A, Suwanagool S: Safety and efficacy of a simplified fixed-dose combination of stavudine, lamivudine and nevirapine (GPO-VIR) for the treatment of advanced HIV-infected patients: a 24-week study. J Med Assoc Thai 2004, 87:760-767.

26. Montaner JS, Cahn P, Zala C, Casssetti LI, Losso M, Hall DB, Wruck J, McDonough M, Gigliotti M, Robinson PA: Randomized, controlled study of the effects of a short course of prednisone on the incidence of rash associated with nevirapine in patients infected with HIV-I. J Acquir Immune Defic Syndr 2003, 33:4 I-46.

27. Knobel H, Miro JM, Domingo P, Rivero A, Marquez M, Force L, Gonzalez A, De Miguel V, Sanz J, Boix V, Blanco JL, Locutura J: Failure of a short-term prednisone regimen to prevent nevirapine-associated rash: a double-blind placebo-controlled trial: the GESIDA 09/99 study. I Acquir Immune Defic Syndr 200I, 28:14-18.

28. Dailly E, Billaud E, Reliquet $\mathrm{V}$, Breurec $\mathrm{S}$, Perre $\mathrm{P}$, Leautez $\mathrm{S}$, Jolliet $\mathrm{P}$, Bourin M, Raffi F: No relationship between high nevirapine plasma concentration and hepatotoxicity in HIV-I-infected patients naive of antiretroviral treatment or switched from protease inhibitors. Eur J Clin Pharmacol 2004, 60:343-348.

\section{Pre-publication history}

The pre-publication history for this paper can be accessed here:

http://www.biomedcentral.com/1471-2334/5/67/prepub

\section{Publish with Bio Med Central and every scientist can read your work free of charge}

"BioMed Central will be the most significant development for disseminating the results of biomedical research in our lifetime. "

Sir Paul Nurse, Cancer Research UK

Your research papers will be:

- available free of charge to the entire biomedical community

- peer reviewed and published immediately upon acceptance

- cited in PubMed and archived on PubMed Central

- yours - you keep the copyright

Submit your manuscript here:

http://www.biomedcentral.com/info/publishing_adv.asp 